\title{
Impact of Cooperative Learning on the Achievement of EFL Tertiary Level Learners: A Case-Study of a Mainstream University in a Middle Eastern Country
}

\author{
Khalid Azim Khan ${ }^{1}$, Hazrat Ali ${ }^{1}$, Shahid Azim Khattak ${ }^{2}$ \& Shaukat Khan ${ }^{2}$ \\ ${ }^{1}$ Department of Humanities, Makkah Community College, Umm Al-Qura University, Makkah, Saudi Arabia \\ ${ }^{2}$ English Language Center, Collge of Social Sciences, Umm Al-Qura University, Makkah, Saudi Arabia \\ Correspondence: Khalid Azim Khan, Makkah Community College, Umm Al-Qura University, Makkah, Saudi \\ Arabia. E-mail: kakhan@uqu.edu.sa
}

Received: October 25, $2017 \quad$ Accepted: November 18, $2017 \quad$ Online Published: December 23, 2017
$\begin{aligned} & \text { doi:10.5539/ijel.v8n2p168 } \\ & \text { URL: http://doi.org/10.5539/ijel.v8n2p168 }\end{aligned}$

\begin{abstract}
Academic achievement of most of the Saudi EFL learners is generally poor. A lot of research has been done to probe problems of EFL learners but very little attention has been paid to overcome these problems via better classroom environment and teaching strategies. This quasi-experimental study aimed at investigating the impact of cooperative learning on academic achievement of EFL tertiary learners at a mainstream public sector university in a Middle Eastern country. The sample of the study included 50 EFL non-English major male students enrolled at the preparatory year program in the first semester of 1434-35 corresponding to 2014 A.D. Pretest posttest experimental group research design was used for the study. Scores of the pretest and posttest for the two course-based assessments were analyzed using MS Excel 2013 and SPSS Version 20. The results of the study revealed that the experimental group showed better performance in the posttest compared to that of control group, showing that cooperative learning has positive impact on academic achievement of Saudi EFL tertiary level learners. The low achievers and the medium achievers in the EG showed statistically significant improvement after the CL treatment whereas high achievers performed equally well in both CL and traditional setting. Low achievement of Saudi EFL tertiary level learners should be given a serious consideration and proper remedial measures should be implemented. CL can be instrumental in this regard.
\end{abstract}

Keywords: cooperative learning, Saudi EFL learners, academic achievement

\section{Introduction}

\subsection{The Problem}

There is no denying the fact that English has assumed the status of a global language and it has made its way even to those regions in the world where teaching and learning English was considered tantamount to committing a sin or an act of high treason. "English is the dominant language of commerce; it is a worldwide, international, linguistic phenomenon" (Graddol, 2006). Now English is taught and learnt in all parts of the world including the Middle East where until recently English was viewed as a language of the infidels. Saudi Arabia, being the largest country in the region, is also no exception in this regard.

In the past forty years, significant political, social and economic developments have taken place in the Kingdom of Saudi Arabia. The Education sector, besides many others, has witnessed tremendous development with considerable changes in the national curriculum especially English. English, which used to be taught as a foreign language from grade 6th, is now being introduced at grade four in all public schools in the Kingdom (Al-Watan Arabic language daily quoting the Minister of Education, Prince Khalid Al-Faisal in its issue published on Wednesday, May 28, 2014). The government has approved a five-year plan worth more than SR. 80 billion ( $\$ 21.33$ billion) to develop the education sector with a special focus on teachers' training. "The Ministry of Education as well as the Ministry of Higher Education are highly concerned with the pursuit of excellence in effective EFL teaching-learning in the arena of education" Liton (2012, p. 130).

English as a Foreign Language (EFL) was chosen and began to be taught in Saudi schools, colleges and universities because of English being most widely used in international trade, diplomacy, economy and contracts, 
international aviation, higher studies, research, affairs of international cooperation across the globe as well as a shared language of peoples throughout the world. "Saudi Arabia has a vast population of expatriates in relation to citizens' population." (Alresheed, 2012, p. 11). Moreover, it is a lingua franca between the Muslim pilgrims visiting the holy cities of Makkah and Madinah from all over the world.

Despite all out support from the government of Saudi Arabia, Saudi students are lagging behind in English language learning as put by Alshumaimeri (2003) "Teachers have pointed out that students leave the secondary stage without the ability to carry out a short conversation". There are many reasons for the poor performance of Saudi EFL learners. Some of the reasons are listed below:

A) Due to the inherent differences of the two languages in terms of structures, script patterns, syntactical orders, semantic associations, supra segmental features and socio-cultural background.

B) Lack of both intrinsic and extrinsic motivation on the part of learners

C) Scarcity of modern language-teaching methodologies and techniques in classrooms

D) Scarcity of exposure to L2/FL communication in day to day life.

E) English phobia among the learners

\subsection{Statement of the Study}

"Although tremendous efforts have been exerted to improve the teaching-learning process of English, EFL programs in Saudi Arabia still fail to deliver as expected" Fareh (2010, p. 3600). Despite the fact that there has been some good language planning, better curriculum, improved textbooks, cutting-edge infrastructural facilities, efficient and qualified teachers, the performance of the EFL students in Saudi Arabia is not satisfactory. Therefore, it is imperative to seek alternative ways of coping with the problem and to suggest new strategies for the purpose.

\subsection{Question of the Study}

To what extent does cooperative learning have an impact on the academic achievement of Non-English major Saudi EFL tertiary level learners?

\subsection{Significance of the Study}

The significance of this study appears in its attempt to:

1). Contribute to the studies of seeking alternative methods of teaching EFL in order to improve students' academic performance.

2). Help EFL teachers and educators to compare and contrast the impact of various instructional strategies.

3). Help EFL teachers to recognize the importance of group work and cooperation in the classroom.

4). Offer suggestions and recommendations to EFL teachers as how to make the classroom environment friendlier, more participatory and more conducive to learning.

5). Ensure that every learner gets the chance of learning and practicing the target language in the classroom.

\subsection{Review of Literature}

"Cooperative learning is the most extensively researched educational innovation of all time. And the results are clear" (Kagan, 2009, 3.1). The results of majority research are positive. Tons of studies show that cooperative learning boosts achievement more than traditional methods. Kagan $(2009,3.2)$ hold that cooperative learning outperforms competitive and individualistic learning structures across all age levels, subject areas, and almost all tasks. He further mentions that in identifying research-based instructional strategies for boosting achievement, Robert Marzano summarized the results of various meta-analyses of cooperative learning. A meta-analysis combines many research studies to determine an average effect. Across hundreds of research studies, compared with strategies in which students compete with each other or work individually, cooperative learning has an effect size of .78. That is an average of a 28 percentile gain for students in the cooperative learning classrooms. To state it in classroom terms, if a student scoring 50 in a traditional classroom were placed in a cooperative classroom, on average the student would be scoring 78! The number of studies along with the size and consistency of the findings make cooperative learning one of the best approaches to boosting achievement.

As mentioned above, cooperative learning has been researched for its impact on students' academic achievements in various subjects on various levels of their schooling in different regions of the world. Majority of the results show positive trends. 
Similarly, Nguyen (2010) in her study "Cooperative Learning and ESL Students' Participation" tried to determine the impact cooperative learning had on ESL students' participation in a second grade classroom, and to examine ESL students' attitudes toward cooperative learning. The results of the study indicated that ESL students participated more frequently during cooperative group learning than in the whole group; and students also increased their use of academic language during cooperative learning instruction.

In her attempt to build small learning communities in the classroom in order to see their effect on students achievement, Caryn Asherson of California State University conducted an action research on "Cooperative Learning: We Instead of Me". She believed that many students enter school without caring support system. She presumed that if classmate's success was tied together, group members would feel an obligation to do their best for the sake of the team. The research did reveal that cooperative learning can lead to improvements in motivation and interpersonal relationships among students.

Cooperative learning is comparatively new to the middle-eastern region especially Saudi Arabia. However researchers are showing great interest in this area. In the studies conducted so far, the effects of CL on Saudi students have been found to be positive in different areas in various subjects. Both teachers and leaners have shown positive attitudes towards CL strategy.

Basamah (2002), in her study investigated the attitudes of principals and teachers towards implementing cooperative learning methods at girls' private middle schools in Jeddah, Saudi Arabia. Additionally, factors affecting the implementation of cooperative learning at the schools were assessed. Her subjects consisted of principals and teachers of 30 girls' private middle schools. The results of this study indicated that the overall attitudes of principals and teachers towards implementing cooperative learning methods were positive. The majority of the principals evaluated cooperative methods as a beneficial, $87 \%$ were willing to implement cooperative methods, $83 \%$ believed that their teachers could implement such methods, and most of them would support the implementation of cooperative learning methods.

There is a need to disseminate the results and positive aspects that CL has been showing, throughout the world, among Saudi teachers and learners. Proper training and assistance in implementation of CL in the classrooms would pave the way to acceptance of the new learning strategy in Saudi Arabia. Algarfi (2010) in his study titled "Teachers' and pupils' perceptions of and responses to cooperative learning methods within the Islamic Culture courses in one secondary school in Saudi Arabia" has investigated the development and implementation of cooperative learning in two Saudi classrooms seeking the perspectives of teachers and pupils to gather their opinion regarding changes to their classroom practice.

The study revealed a need for wider consideration and development of cooperative learning in both pre-service and in-service programs in Saudi Arabia and the implications for number of stakeholders to realize the aims presented.

In his meta-analysis, Saber (1999) [in Basamah 2002] reviewed research on cooperative learning in Arab countries. Saber found that the cooperative learning groups' achievement mean score was higher than the traditional groups' achievement mean score for students in high schools and middle schools in different subjects such as math, science, language, and social studies.

Mansour \& Alhodithy (2007) conducted their study by focusing on ways of improving the teaching and learning process in response to the current changes in the Saudi education system. They had planned to discuss the possibility of introducing new methodologies into the SA education system, based on research into CL, which has had a widespread effect in other countries.

The findings of the study showed that the current classrooms and the school environment in Saudi Arabia do not accommodate the $\mathrm{CL}$ principles and practices. Moreover, where cooperative grouping was found, it lacked the features recommended in the literature for effective CL. Also, the study identified some of the constraints which affected the implementation of CL in Saudi secondary schools. However, the results have paramount implications for the school system, classroom teaching and students' learning in Saudi Arabia.

Cooperative Learning has shown positive results in almost all areas of the EFL teaching and learning processes in all regions of the world. Saudi Arabia is also not an exception. Alharbi (2008) in her study investigated the effects of the use of cooperative learning method in English as a second language reading comprehension performance and how it improves the students' second language, their attitudes toward cooperative learning, and their motivation toward reading. There were significant differences between the two groups in the reading comprehension performance and in students' attitudes toward cooperative learning, which favored the experimental group. Finally, the researcher discussed educational implications for each variable and suggested 
several recommendations for implementation and further research.

Results of this analysis indicated no significant difference between experimental and comparison groups for all measures. However, the analysis indicated significance differences between experimental and comparison groups on post-measures of vocabulary and fluency, and students' attitudes toward cooperative learning. Conversely, the result showed no significant difference between experimental and comparison groups on post-measures of reading comprehension and students' motivation toward reading.

When grouped cooperatively, Saudi students have shown positive results in the EFL context. Mahmoud (2014) used Cooperative language learning (CLL) approach to encourage second-year university students at the college of languages and translation, at Al-Imam University to learn from their peers so that they could develop their writing skills. The findings revealed that the students' scores in writing were higher for the post-test than the pre-test at the significance level of .001 after being subject to this kind of treatment. However, it must be stated that the degree of improvement was not extremely high as students still made some mistakes with regard to the grammar and syntax. As for the attitude scale, the results obtained proved that the students developed positive attitudes towards using the cooperative learning approach to develop language skills in general and to develop their writing skills in particular.

In the Saudi context, Balal (2013) examined the effects of cooperative learning on EFL learners' performance in Saudi Arabia. The sample consisted of 32 students who were selected randomly from two classes of the second year secondary school students in Riyadh in Saudi Arabia. The experimental class was taught through cooperative learning for one semester with the methods of Student Teams-Achievement Divisions (STAD). The control class was taught in the traditional method of Grammar Translation with some of the Audio- Lingual approach. Data were collected via observation and tests(pre-test and post-test). The researcher found that students taught through cooperative learning achieved better academic performance inside the classroom and in the final year exam; the researcher found that the use of cooperative learning method has positive effects on EFL learners' performance and cooperative learning approach is more effective than the other non-cooperative learning approaches.

The results are discussed in the light of theory and research on cooperative learning, task-based language teaching and the roles of learners, teachers and course books. The study is descriptive in nature. The researcher has noted that many group activities in the course books were merely presented without proper description of their implementation. Similarly, very few group activities were found to be cooperative in nature.

\subsection{Gap in Research}

In the preceding section, it is clear that cooperative learning has the potential of becoming a fruitful instructional strategy for EFL teaching and learning. Researchers have investigated the effect of CL on students' academic achievement in various subjects and at different levels in Saudi Arabia. Similarly, EFL achievement of Saudi students with regard to CL in different skills areas have also been researched up to secondary level. The researcher has not found any study investigating impact of CL on Saudi students' academic achievement at tertiary level. Thus an effort is being made to find out if there is any impact of CL on academic achievement of Saudi EFL tertiary level learners

\section{Methods and Procedures}

\subsection{Design of the Study}

In line with the research question, a quasi-experimental pretest posttest research design was chosen for the study to investigate the impact of cooperative learning on students' achievement. It aimed at collecting descriptive and analytical data concerning impact of cooperative learning on academic achievement of Saudi EFL learners at Tertiary level. For the purpose of study fifty students and two teachers were selected. The students were selected from two groups of male students enrolled in the first semester of the preparatory year program (PYP) in the year 1435 A.H corresponding to 2014 AD at Umm Al-Qura University in Makkah. Participants were fifty $(\mathrm{n}=50)$ Saudi male students. They were sixteen to twenty five years old. The mean of their age was twenty one years. The teachers were faculty members of the English Language Center (ELC) at the College of Social Sciences in Umm Al-Qura University.

\subsection{Intervention}

Immediately after the midterm examination, the CL treatment was introduced at the experimental group (EG) in the eleventh week. This helped for the obvious reason that learners had got used to the university environment and had got some experience of studying English in the first half of the semester. Up to this point, they had developed some impression of their teacher, the teaching methodology and English language as a whole. 
Pre-Intermediate New Headway Plus, Special Edition by John and Liz Soars of the Oxford University Press was the course book.

Sufficient practice was given to students in order to reinforce those targeted language items through many activities designed by the teacher which were mostly communicative in nature. Then the teacher would start with the real lesson with "Starters" given at the beginning of every unit which served as a base for evaluating students' basic knowledge of the targeted language item. Then the whole unit in each chapter was taught using CL structures e.g., STAD, Jigsaw II, Numbered Heads together and Inside-Outside Circles. All the aforementioned CL structures were implemented throughout the chapters in all the four skills especially Reading, Speaking and Listening along with Vocabulary and Grammar, wherever applicable. Majority of the students showed great interest and participated with enthusiasm in a relatively new teaching learning environment provided by CL.

\subsection{Students' Teaming}

The students were assigned heterogeneously to 5 teams of five students each on the basis of their Midterm examination scores. Each group had at least one high achiever and two medium achievers and two low achievers. A high achiever among team members was selected as the Team Leader. Another bright student was selected as his deputy.

These groups were named after famous Saudi football league teams namely Al-Fateh, Al-Nasr, Al-Hilal, Al-Ahli and Al-Ettihad in order to spur learners' interest. Small scorecards were designed carrying the names of the teams as well as their members. The teacher used these cards for assigning group marks based on successful completion of group activities.

\subsubsection{Description of Teams}

Students in the experimental group were named according to their roll number in the class, with English Alphabets where the first on the roll gets the name A, the second as B and so on. The last student in the group was named "Y" corresponding to roll number 25. Experimental Group (EG) was divided into 5 teams, consisting of 5 students each. These teams were made heterogeneously according to the students result in the Midterm examination. Every effort was made to ensure inclusion of at least one high achiever and one medium achiever in all groups. Based on heterogeneous groupings, the aforementioned teams consisted of the following members as shown in table 1 below.

Table 1. CL teams mean scores in MT

\begin{tabular}{lll}
\hline Team & Team Members & MT Mean \% \\
\hline Al-Fateh & A, H, Q, W, Y & $48 \%$ \\
Al-Nasr & D, M, O, P, X & $46 \%$ \\
Al-Hilal & G, J, N, R, U & $48 \%$ \\
Al-Ahli & B, F, I, L, S & $44.6 \%$ \\
Al-Ettihad & C, E, K, T, V & $46.6 \%$ \\
\hline
\end{tabular}

$10 \%$ extra marks were promised to groups that improve on their mean scores during the period of the study. These marks were to be dispensed from the $20 \%$ marks allocated for attendance, class participation and homework.

\subsection{Instrument of the Study and Its Administration}

To study the impact of cooperative learning on students' academic achievement, the researchers mainly relied on course-based assessments (Midterm and Final term examinations) of the two groups for data collection.

\subsubsection{Course-Based Assessments (Mid Term and Final Term Examinations)}

The instrument in this study included the scores from the two major course-based assessments i.e., Midterm and Final Term examinations, held at the Preparatory Year, gathered in the middle and the end of the semester. The major reason for including the scores of these examinations was to examine if cooperative learning had any impact on the students' academic achievement. The results of the Midterm and Final term examinations also served as pretest and posttest scores respectively for the three levels of achievers among students under study.

The first course-based assessment (Midterm examination) tested the students on the materials from chapter 1 to chapter 14 of the Elementary New Headway Plus, Special Edition by John and Liz Soars of the Oxford University Press. The second course-based assessment (Final Term examination) covered from chapter 1 to chapter 14 of the course-book "Pre-Intermediate New Headway Plus, Special Edition by John and Liz Soars of 
the Oxford University Press". The final term examination was a longer version of the midterm examination in terms of assessment style and question items. The test designers of these examinations were English teachers teaching at the English Language Center of the College of Social Sciences in Umm Al-Qura University.

The test items in the course-based examinations consisted of listening comprehension (20\%), vocabulary (30\%), grammar (30\%) and reading comprehension through multiple choice questions $(20 \%)$. Three language skills, i.e., listening, reading, and writing, were tested in these examinations whereas assessment of speaking skills was not included in these two assessments.

The centralized exam system of the ELC is proved to be reliable. The system selects MCQ's items from the questions bank fed by the Exam Committee at the ELC. Such MCQ's cover almost all the intended learning outcomes set forth for the students in that particular stage.

The Final term examination carrying 50 marks consisted mainly of three sections. The first section contained two parts (A and B). Two recordings were presented for listening with 10 MCQ's to choose from; 5 questions for each listening items. The second section (Part C) Reading comprehension consisted of two reading passages, contained 10 MCQ's; 5 MCQ's per passage. The third section (Part D) consisted of Vocabulary and Grammar which contained 30 items multiple choice questions (MCQ's). There were a total of four different versions of Final (End) term examination, marked as A, B, C and D. All exam versions carried the same number of items and sections and the style of questions were the same.

\subsection{Procedures Followed in Analyzing the Data}

The data collected for analysis to examine the impact of cooperative learning in this study included (1) the scores of the two course-based assessments. The Independent Samples t-test and Paired Samples t-test were utilized to check if there was any significant difference in their scores of the two course-based examinations between the two groups in the pretest and posttest. The scores of the high, medium and low-achievers in EG were computed using SPSS version 20.0 to compare the inter-group differences.

\subsection{Scoring the Two Course-Based Assessments}

The first course-based assessment (Midterm Exam) carried 30 Marks. Almost all the test items (MCQ's) carried half $(1 / 2)$ a mark per item. The Exam Committee at the ELC was responsible for checking and marking of these tests. The tests were auto-checked through special Scantron machines which marked the tests and compiled results automatically. Similarly, the second course-based assessment (Final Term Exam) carried 50 marks and each test item was assigned half (1/2) a mark per item. The exam papers were auto-checked through Scantron machines.

\section{Results}

\subsection{Results of the Course-Based Assessments}

\subsubsection{First Course-Based Assessment (Midterm Examination)}

The first course-based assessment was taken by both CG and EG out of 30 marks. Table 2 below shows the scores of Midterm examination for both groups.

Table 2. Students' MT mean scores for CG and EG

\begin{tabular}{llll}
\hline Groups & MT mean & MT \% & SD \\
\hline Control Group (CG) & 13.84 & 46.10 & 13.18 \\
Experimental Group (EG) & 14 & 46.63 & 16.36 \\
\hline
\end{tabular}

As indicated in table 2 above, the mean percentage scores of the EG and CG were 46.63 and 46.09 respectively. It shows almost no difference between the mean scores of the two groups. However further statistical analysis was conducted to show whether the difference was significant or otherwise.

Table 3. MT Group statistics for CG and EG

\begin{tabular}{llllll}
\hline Group Statistics & & & & \\
& Group type & N & Mean & Std. Deviation & Std. Error Mean \\
\hline Mid Term Percentage \% & Experimental Group & 25 & 46.6320 & 16.35771 & 3.27154 \\
& Control Group & 25 & 46.0960 & 13.17812 & 2.63562 \\
\hline
\end{tabular}


Table 4. MT t-test results for CG and EG

\begin{tabular}{|c|c|c|c|c|c|c|}
\hline \multicolumn{7}{|c|}{ Independent Samples Test } \\
\hline & & \multicolumn{5}{|c|}{ t-test for Equality of Means } \\
\hline & & \multirow[t]{2}{*}{$\mathrm{t}$} & \multirow[t]{2}{*}{ df } & \multirow{2}{*}{$\begin{array}{l}\text { Sig. } \\
\text { (2-tailed) }\end{array}$} & \multicolumn{2}{|c|}{$\begin{array}{l}95 \% \text { Confidence Interval of the } \\
\text { Difference }\end{array}$} \\
\hline & & & & & $\begin{array}{l}\text { Difference } \\
\text { Lower }\end{array}$ & Upper \\
\hline Mid Term \% & Equal variances assumed & .128 & 48 & .899 & -7.91094 & 8.98294 \\
\hline & Equal variances not assumed & .128 & 45.92 & .899 & -7.92084 & 8.99284 \\
\hline
\end{tabular}

As shown in the tables 3 and 4 above, the statistical analysis of the midterm examination results data of the Independent Samples t-test show no significant difference $(\mathrm{p}=0.899>0.05)$ between the two groups. This means that both the groups (CG and EG) had almost similar results before the treatment and this provided the researcher a sound platform to carry out his experiment on similar groups.

\subsubsection{Second Course-Based Assessment (Final Term Examination)}

The second course-based assessment (Final Term examination) was taken by both CG and EG out of 50 marks. Table 5 below show the mean scores of Final term examination for both groups.

Table 5. Students' mean FT scores

\begin{tabular}{llll}
\hline Groups & FT mean & FT \% & SD \\
\hline Control Group & 25.04 & 50.08 & 19.20 \\
Experimental Group & 30.08 & 60.16 & 15.17 \\
\hline
\end{tabular}

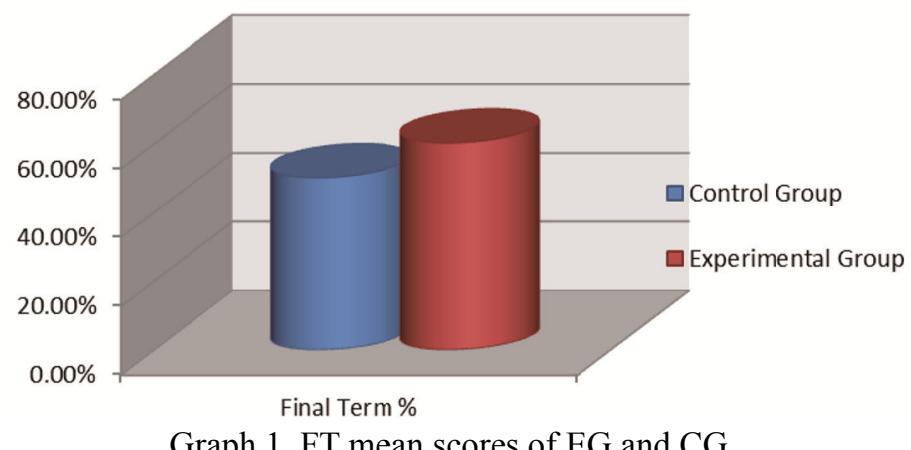

Graph 1. FT mean scores of EG and CG

The second course-based assessment took place at the end of the first semester (end of the treatment period for EG). As shown in the table 5 and graph 1 above, the mean percentage score of CG and EG was $50.08 \%$ and $60.16 \%$ respectively. There was obvious difference in the means for the two groups. However, further statistical analysis will be done to see whether this difference was significant or otherwise.

Table 6. FT group statistics for EG and CG

\begin{tabular}{llllll}
\hline Group Statistics & & & & \\
& Group type & N & Mean & Std. Deviation & Std. Error Mean \\
\hline Final Term & Experimental Group & 25 & 60.1600 & 15.69416 & 3.13883 \\
Percentage \% & Control Group & 25 & 50.0800 & 19.19618 & 3.83924 \\
\hline
\end{tabular}


Table 7. Independent samples t-test for EG and CG

\begin{tabular}{|c|c|c|c|c|c|c|}
\hline \multicolumn{7}{|c|}{ Independent Samples Test } \\
\hline & & \multicolumn{5}{|c|}{ t-test for Equality of Means } \\
\hline & & \multirow[b]{2}{*}{$\mathrm{t}$} & \multirow[b]{2}{*}{$\mathrm{df}$} & \multirow{2}{*}{$\begin{array}{l}\text { Sig. } \\
\text { (2-tailed) }\end{array}$} & \multicolumn{2}{|c|}{$\begin{array}{l}95 \% \text { Confidence Interval } \\
\text { of the Difference }\end{array}$} \\
\hline & & & & & Lower & Upper \\
\hline Final Term & Equal variances assumed & 2.033 & 48 & .048 & .10920 & 20.05080 \\
\hline Percentage $\%$ & Equal variances not assumed & 2.033 & 46.176 & .048 & .09901 & 20.06099 \\
\hline
\end{tabular}

As shown in the tables 6 and 7 above, the result of statistical analysis for the FT scores shows significant difference between the $\mathrm{CG}$ and the $\mathrm{EG}(\mathrm{p}=0.048<0.05)$. This means that $\mathrm{EG}$ exceled $\mathrm{CG}$ in terms of academic achievement after the CL treatment. The experimental group which was taught using cooperative learning techniques bears positive impact whereas the control group taught through traditional methods had comparatively less improved results. Graph 2 below shows the difference between EG and CG for the both MT and FT examinations.

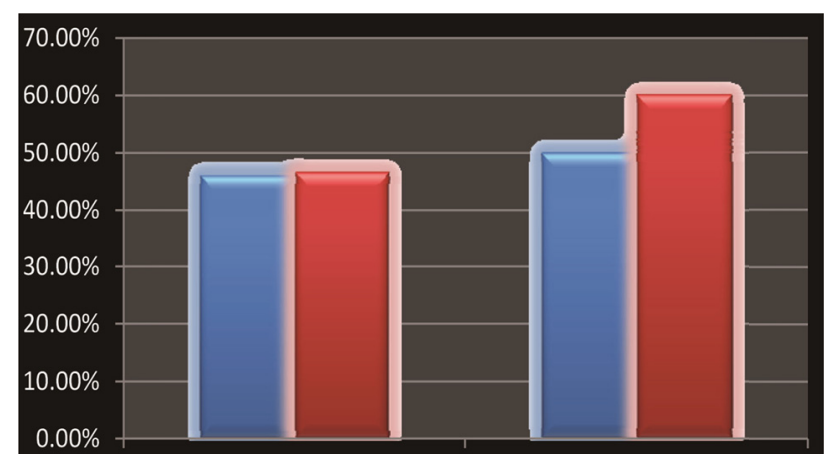

Graph 2. MT and FT mean scores for CG and EG

The statistical analysis for intra-group comparison of MT and FT scores for experimental group as shown in the table below indicated a mean percentage improvement of $13.52 \%$. Further statistical analysis would confirm whether this improvement was significant or not.

Table 8. Paired sample statistics of MT and FT for EG

\begin{tabular}{lllll}
\hline \multicolumn{2}{l}{ Paired Samples Statistics } & & & \\
\hline & Mean & N & Std. Deviation & Std. Error Mean \\
Pair 1 MT & 46.6320 & 25 & 16.35771 & 3.27154 \\
FT & 60.1600 & 25 & 15.69416 & 3.13883 \\
\hline
\end{tabular}

Table 9. Paired samples t-test results for MT and FT for

\begin{tabular}{|c|c|c|c|c|c|c|c|c|}
\hline \multicolumn{9}{|c|}{ Paired Samples Test } \\
\hline & \multicolumn{8}{|c|}{ Paired Differences } \\
\hline \multirow{3}{*}{$\begin{array}{l}\text { Pair } 1 \text { MT - } \\
\text { FT }\end{array}$} & & & & $95 \%$ Confic & terval of the Difference & & & \\
\hline & Mean & Std. Deviation & Std. Error Mean & Lower & Upper & $\mathrm{T}$ & df & Sig. (2-tailed) \\
\hline & -13.5280 & 13.66841 & 2.73368 & -19.17004 & -7.88596 & -4.949 & 24 & .000 \\
\hline
\end{tabular}

As shown in the tables above, the experimental group showed tremendous improvement in the CL setting in the posttest results as compared to the results of pretest in the traditional setting. The Paired Samples t-test analysis indicates $(\mathrm{p}=0.000<0.05) \mathrm{t}=-4.949$ at the degree of freedom level of 24 . Such an improvement is highly significant. This means that the experimental group performed significantly well when cooperative treatment was introduced.

Similarly the statistical analysis for intra-group comparison for control group as shown in the tables below 
indicated a mean percentage improvement of $3.98 \%$. Further statistical analysis would confirm whether this improvement was significant or not.

Table 10. Paired samples statistics of MT and FT for CG

\begin{tabular}{|c|c|c|c|c|}
\hline \multicolumn{5}{|c|}{ Paired Samples Statistics } \\
\hline \multirow{3}{*}{ Pair 1 MT FT } & Mean & $\mathrm{N}$ & Std. Deviation & Std. Error Mean \\
\hline & 46.0960 & 25 & 13.17812 & 2.63562 \\
\hline & 50.0800 & 25 & 19.19618 & 3.83924 \\
\hline
\end{tabular}

Table 11. Showing paired samples t-test results for MT and FT for CG

\begin{tabular}{|c|c|c|c|c|c|c|c|c|}
\hline \multicolumn{9}{|c|}{ Paired Samples Test } \\
\hline & \multicolumn{8}{|c|}{ Paired Differences } \\
\hline & \multirow[b]{2}{*}{ Mean } & \multirow[b]{2}{*}{ Std. Deviation } & \multirow[b]{2}{*}{ Std. Error Mean } & \multicolumn{3}{|c|}{$\begin{array}{l}95 \% \text { Confidence Interval of } \\
\text { the Difference }\end{array}$} & \multirow[b]{2}{*}{$\mathrm{df}$} & \multirow[b]{2}{*}{ Sig. (2-tailed) } \\
\hline & & & & Lower & Upper & $\mathrm{T}$ & & \\
\hline Pair $1 \mathrm{MT}$ - FT & -3.98400 & 11.68427 & 2.33685 & -8.80703 & .83903 & -1.705 & 24 & .101 \\
\hline
\end{tabular}

As shown in the tables above, the control group showed comparatively lesser improvement in the traditional setting in the posttest results as compared to the results of pretest. The paired samples t-test analysis results indicate $(\mathrm{p}=0.101>0.05) \mathrm{t}=-1.705$ at the degree of freedom level of 24. Such an improvement is considered insignificant. This means that the control group did not perform well in both pretest and posttest in the same traditional teaching set up.

\subsection{Cooperative Intra-class Teams Progress}

The experimental group was heterogeneously assigned into five teams, based on their midterm examination marks. These teams were named after famous Saudi league football teams. The progress of all teams were kept and recorded by the teacher. Graph 3 and table 12 below show inter-teams results of the experimental group.

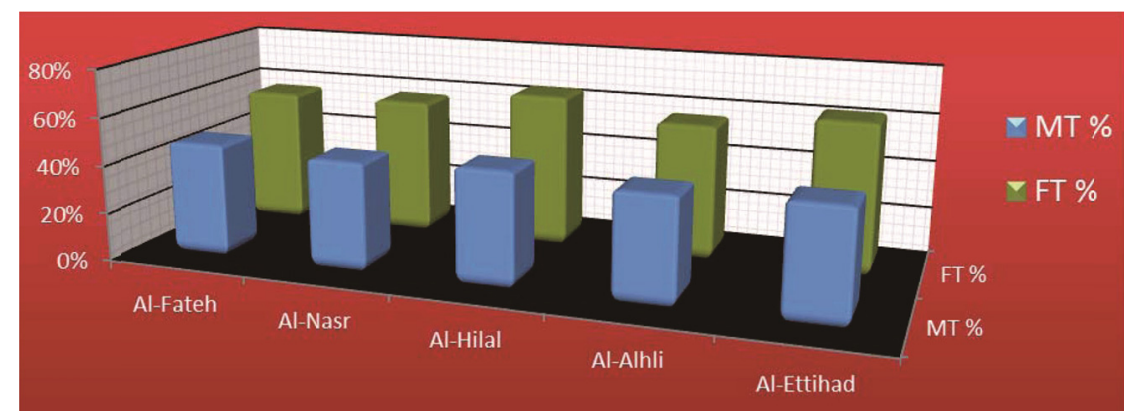

Graph 3. Intra-teams Performance in MT and FT

Table 12. Intra-teams performance in MT and FT

\begin{tabular}{llll}
\hline Teams & Midterm mean $\%$ & Final Term mean $\%$ & Progress $\%$ \\
\hline Al-Fateh & $48 \%$ & $57.6 \%$ & $9.6 \%$ \\
Al-Nasr & $46 \%$ & $58 \%$ & $12 \%$ \\
Al-Hilal & $48 \%$ & $64.8 \%$ & $16.8 \%$ \\
Al-Ahli & $44.6 \%$ & $57.2 \%$ & $12.6 \%$ \\
Al-Ettihad & $46.6 \%$ & $63.2 \%$ & $16.6 \%$ \\
\hline
\end{tabular}

As shown in graph 3 and table 12 above, Al-Hilal team showed the most improvement (16.8\%) and got first position. Al-Ettihad team stood second with (16.66\%) improvement and Al-Ahli team took third position showing (12.6\%) improvement. As promised, all the teams were compensated with the $20 \%$ marks allotted to homework and class participation, based on their performance. 


\section{Discussion}

This part presents a discussion of the hypothesis and question of the study in light of data analysis and interpretations of the results. To test the hypothesis of the study, the average and mean scores of the two course-based assessments were calculated and compared, using SPSS version 20.0 and Microsoft Excel version 2010.

\subsection{The Hypothesis}

There is no statistically significant impact of cooperative learning on academic achievement of Saudi EFL tertiary learners.

For the first main hypothesis of this study, the means of overall results in both course-based assessments for both experimental and control groups were calculated and compared. Table 13 below shows the results.

Table 13. MT and FT scores for CG and EG

\begin{tabular}{lllll}
\hline & CG & EG & p value & Significance \\
\hline MT \% & 46.10 & 46.63 & 0.899 & Not Significant \\
FT \% & 50.08 & 60.16 & 0.048 & Significant \\
Percentage Improvement & 3.98 & 13.53 & & \\
\hline
\end{tabular}

The students level in the pretest in both CG ad EG was almost the same ( $\mathrm{p}=0.899>0.05)$. However, students in the CG showed lesser improvement of $3.98 \%$ on the mean scores of their FT in the traditional setting whereas those in the EG showed improvement of $13.53 \%$. The difference between CG and EG on the posttest score is significant $(\mathrm{p}=0.048<0.05)$. This level of improvement indicated significantly positive impact. This is the answer to our question: To what extent does cooperative learning have an impact on academic achievement of Non-English major Saudi EFL learners? This means that students' performance in the control group remained the same whereas that of the experimental group improved. When cooperative learning was introduced, the students' performance improved significantly. Thus the main null hypothesis was rejected.

The above mentioned results of the present study revealed that cooperative learning had a positive impact on academic achievement of EFL tertiary level learners. This means with CL treatment, student's academic achievement increased as compared to traditional methods. This result is consistent with studies reported by Ajaja (2010), Gubbad (2010), Hsiung (2012) and Balal (2013) who found that CL plays a significant role in improving students' academic achievement. Similarly, CL was found to be feasible for the Low and Medium Achievers who showed tremendous improvements in their academic achievements. However, the performance of High Achievers was not affected by CL and they performed equally well in both CL and traditional settings. This result is consistent with studies reported by Stockdale (2004) and Liang (2002) who found that CL is best suited for Low and Medium Achievers.

\subsection{Conclusion}

The present study was conducted to explore the possible bearings of "Cooperative learning" on the academic achievements of Saudi EFL learners at tertiary level. Thus, the research claims a distinguished place in the galaxy of already established research works due to the acknowledged fact that it was unprecedented work in the field and in this region. The nature, purpose, motive and rationale behind this humble endeavor were purely pedagogical. The strong academic background of the researchers, in addition to their firsthand experience of teaching both at national and international institutions of repute, made the present attempt easy and commendable. The net outcomes of the research are not only important because they will facilitate the teaching learning process but will also open new vistas for the upcoming researchers and academicians. The present study is part of a larger study by the principal researcher and is limited to male students of the preparatory year residing in the Makkah Province. It may be replicated to investigate the impact of CL on female students of the same area or male students of another area and at different levels.

\section{References}

Ajaja, O. P., \& Eravwoke, O. U. (2010). Effects of Cooperative learning Strategy on Junior Secondary School Students Achievement in Integrated Science. Electronic Journal of Science Education, 14(1), 1.

Algarfi, A. (2010). Teachers' and pupils' perceptions of and responses to cooperative learning methods within the Islamic culture courses in one secondary school in Saudi Arabia. University of Southampton, School of Education, Doctoral Thesis, p. 280. 
Alharbi, L. A. (2008). The Effectiveness of Using Cooperative Learning Method on ESL Reading Comprehension Performance, Students' Attitudes toward CL, and Students' Motivation toward Reading of Secondary Stage in Saudi Public Girls' Schools. A PhD Dissertation submitted to Department of Curriculum \& Instruction/Literacy Studies, The College of Human Resources and Education, Morgantown, West Virginia University, USA.

Alresheed, S. (2012). Exploring the nature of the Saudi English teachers'beliefs and attitudes toward EFL and its effect on their teaching practice. A paper presented in The Saudi Scientific International Conference 2012, London.

Al-Shumaimeri, Y. A. N. (2003). A study of classroom exposure to oral pedagogic tasks in relation to the motivation and performance of Saudi secondary learners of English in a context of potential curriculum reform. Unpublished Ph.D.Thesis, University of Leeds, Leeds.

Asherson, C. (n. d.). Cooperative Learning: We Instead of Me. California State University, Northridge. Retrieved from www.csun.edu/ cla49614/coursework/697/Action_Research_Project.doc

Balal, B. (2013). The Effects of using Cooperative Learning on EFL learners' performance'. The European Conference on Language Learning 2013, Official Conference Proceedings 2013.

Basamah. (2002). Principals' and teachers'attitudes toward implementing cooperative learning methods at girls' private middle schools in Jeddah, Saudi Arabia. A doctoral dissertation submitted to the Graduate Faculty of the School of Education, University of Pittsburgh, USA.

Fareh, S. (2010). Challenges of teaching English in the Arab world: Why can't EFL programs deliver as expected? Procedia Social and Behavioral Sciences, 2, 3600-3604, 1877-0428. Amsterdam: Elsevier Ltd.

Gömleksiz, M. N. (2007). Effectiveness of cooperative learning (jigsaw II) method in teaching English as a foreign language to engineering students (Case of Firat University, Turkey). European Journal of Engineering Education, 32(5), 613-625. https://doi.org/10.1080/03043790701433343

Graddol, D. (2006). "English Next" British Council 2006 (p. 128). Retrieved from www.britishcouncil.org/learning-research

Gubbad, A. H. (2010). The Effect of Cooperative Learning on the Academic Achievement and Retention of the Mathematics Concepts at the Primary School in Holy Makkah. J. King Saud Univ. Edu. Sci. \& Islamic Studies, 22(2), 13-23, Riyadh (2010/1431H.)

Herrmann, K. J. (2013). The impact of cooperative learning on student engagement: Results from an intervention. Active Learning in Higher Education, 14(3), 175-187. https://doi.org/10.1177/1469787413498035

Hsiung, C. M. (2012). The Effectiveness of Cooperative Learning. Journal of Engineering Education, 101(1), 119-137. Retrieved from http://www.jee.org

Kagan, D. S., \& Kagan M. (2009). Kagan Cooperative Learning (p. 484). E-Book San Clemente CA 92673, Kagan Publishing.

Kagan, S. (1999). Cooperative Learning: Seventeen Pros and Seventeen Cons Plus Ten Tips for Success. San Clemente, CA: Kagan Publishing. Kagan Online Magazine, Winter, 1999. Retrieved from www.KaganOnline.com

Liton, H. A. (2012). Developing EFL Teaching and Learning Practices in Saudi Colleges: A Review. International Journal of Instruction, 5(2).

Mahmoud, M. A. (2014). The Effectiveness of Using the Cooperative Language Learning Approach to Enhance EFL Writing Skills among Saudi University Students. Journal of Language Teaching and Research, 5(3), 616-625. ACADEMY PUBLISHER Manufactured in Finland. https://doi.org/10.4304/jltr.5.3.616-625

Mansour, N., \& Alhodithy, A. (2007). Cooperative Learning in Saudi Arabia schools: teachers' understanding and intentions. A paper presented at the British Educational Research Association (BERA) annual conference at Institute of Education, University of London, UK, September 5-8, 2007.

Nguyen, A. (2010). Cooperative Learning and ESL Students' Participation. A Capstone submitted for the degree of Master of Arts in English as a Second Language Hamline University Saint Paul, MN, USA.

Saber, M. (1999). Effect of Cooperative Learning Methods in Secondary Female Students' Achievement of Psychology and their Attitudes toward Cooperative Learning Strategies". In Basamah 2002, "Principals' and teachers' attitudes toward implementing cooperative learning methods at girls' private middle schools 
in Jeddah, Saudi Arabia. A PhD thesis submitted to the Graduate Faculty of the School of Education, University of Pittsburgh, USA.

Sarobol, N. (2012). Implementing Cooperative Learning in English Language Classroom: Thai University Students' Perceptions. The International Journal of Interdisciplinary Social Sciences, 6(10). https://doi.org/10.18848/1833-1882/CGP/v06i10/52170

Slavin R. E. (1999). Comprehensive Approaches to Cooperative Learning. Theory into Practice, 38(2). College of Education, The Ohaio State University.

Slavin, R. (1995). Cooperative learning: Theory, Research, and Practice (2nd ed.). Boston, MA: Allyn and Bacon. https://doi.org/10.1080/00405849909543835

Stockdale, S. L., \& Williams, R. L. (2004). Cooperative Learning Groups at the College Level: Differential Effects on High, Average, and Low Exam Performers. Journal of Behavioral Education, 13(1), 37-50. https://doi.org/10.1023/B:JOBE.0000011259.97014.94

\section{Copyrights}

Copyright for this article is retained by the author(s), with first publication rights granted to the journal.

This is an open-access article distributed under the terms and conditions of the Creative Commons Attribution license (http://creativecommons.org/licenses/by/4.0/). 